\title{
BOAS PRÁTICAS DE FABRICAÇÃO DE ALIMENTOS EM FARINHEIRAS \\ ECOLÓGICAS NO EXTREMO SUL DA BAHIA
}

\section{Giovana Andrade Comper ${ }^{1}$; Giovanna Sousa Santana'; Vinicius Mariguella Alves Botelho'; Mauriceia Costa Carvalho Barros²; Gutto Monzelle Rios Marques ${ }^{3}$}

${ }^{1}$ Graduando (a), IF Baiano campus Teixeira de Freitas, Teixeira de Freitas, Bahia, ${ }^{2}$ Doutora, IF Baiano campus Teixeira de Freitas, Teixeira de Freitas, Bahia, ${ }^{3}$ Mestre, IF Baiano campus Teixeira de Freitas, Teixeira de Freitas, Bahia.

DOI: 10.47094/ICONNECA.2021/26

\section{RESUMO}

O programa de BPF visa o controle e execução de técnicas de produção alimentícia com segurança dos alimentos em locais com recepção, produção e armazenamento de alimentos, além de estar relacionado com higienização de instalações, equipamentos, móveis, controle integrado de vetores, pragas urbanas, higienização de reservatórios de água e saúde dos manipuladores. Objetivou-se apresentar aos manipuladores de alimentos das farinheiras ecológicas da Comunidade de Campo Alegre, Alcobaça-BA, as Boas Práticas de Fabricação (BPF). Foi elaborado um curso com duração de 20 horas para o treinamento de 19 manipuladores de alimentos. Após a conclusão do curso, foi aplicada a lista de verificação das BPF em estabelecimentos produtores/industrializadores de alimentos contida no Anexo II da Resolução RDC no 275/2002, ANVISA. Verificou-se a evolução que os manipuladores concederam após a realização do curso, pois houve a percepção dos pontos que poderiam ser implementados para adequação à norma nos estabelecimentos em questão.

PALAVRAS-CHAVE: Segurança dos alimentos. Legislação. ANVISA.

ÁREA TEMÁTICA: Segurança alimentar, nutrição e saúde.

\section{INTRODUÇÃO}

Pela resolução da ANVISA n ${ }^{\circ}$ 275/2002, todos os processos de produção de alimentos até a comercialização e compra pelo consumidor, precisam seguir normas que garantam de fato um alimento inócuo à saúde, pelo fato da contaminação dos alimentos ser uma das maiores causas de mortalidade humana, principalmente nos grupos mais susceptíveis (crianças e idosos) (BRASIL, 2002). O MAPA descreve uma série de normas a serem seguidas para a produção da farinha, que vão desde o processo de colheita, processamento, equipamentos usados, higienização e empacotamento, e entre outros processos, visando a produção de um produto livre de riscos biológicos e físicos, incluídas no Regulamento Técnico da Farinha de Mandioca instituído pela Instrução Normativa $n^{\circ}$ 52, de 2011, com as alterações da $\mathrm{INn}^{\circ} 58$, de 2020. O treinamento das pessoas que trabalham diretamente com 
o processamento de alimentos é de suma importância na prevenção de grande parte das doenças transmitidas pelos alimentos, que podem ser causadas tanto pelo contato direto do manipulador com o alimento ou pela contaminação cruzada. A falta de conhecimento dos manipuladores faz com que a maioria dos surtos aconteça por um manuseio incorreto do alimento. (FEIN et al., 1995; MARTINEZTOMÉ et al., 2000 ). Por estas e outras razões, desenvolveram-se alguns programas para instruir os manipuladores de alimentos em prol da segurança alimentícia, como o Procedimento Operacional Padrão (POP) e as Boas Práticas de Fabricação (BPF), ambos regulamentados pela Agência Nacional de Vigilância Sanitária - ANVISA, e o Procedimento Padrão de Higiene Operacional (PPHO) regulamentado pelo Ministério da Agricultura, Pecuária e Abastecimento que se refere ao processamento do leite e derivados. Os três programas visam controlar e estabelecer técnicas de produção alimentícia em locais que tem recepção, produção e armazenamento de alimentos, além de estar relacionado com higienização de instalações, equipamentos e móveis, controle integrado de vetores e pragas urbanas, higienização de reservatórios e saúde dos manipuladores. Com a capacitação dos manipuladores em BPF para farinheiras é possível implementar essas ferramentas e garantir que as mesmas sejam mantidas e eficazes na produção de farinha de mandioca pelas farinheiras da Cooperativa de Agricultores do Vale do Itaitinga (CAVI), Comunidade de Campo Alegre, Alcobaça - Bahia , trazendo para o consumidor informação sobre o controle e garantia higiênica-sanitária da farinha além de capacitação profissional rural para manipuladores que trabalham diretamente na produção de farinha.

O objetivo deste trabalho foi capacitar os manipuladores para obter uma maior segurança de alimentos na produção de farinha desenvolvida pela comunidade rural que trabalha em farinheiras ecológicas cooperadas pela CAVI.

\section{METODOLOGIA}

A metodologia adotada propôs a preparação e desenvolvimento do curso de BPF para os manipuladores de alimentos da farinheira ecológica na comunidade do Apaga Fogo do município de Alcobaça - BA O curso foi realizado em março de 2020 e concretizado em duas etapas, com duração de 8 horas de atividades diárias, que incluíam plano de ensino, material didático e organização do espaço de ministração do curso. Foram utilizadas aulas expositivas teóricas e atividades práticas. As atividades práticas foram desenvolvidas nas farinheiras da própria cooperativa. Para atender esses parâmetros, foram utilizados recursos como uso de projetor de imagens, flipchart, cartazes e filmes didáticos. Para as práticas foram utilizados materiais e utensílios para higienização ambiental, bem como indumentária de manipulador de alimentos e EPI's (Equipamentos de Proteção Individual) como luvas, máscaras, toucas, aventais e botas.

A seleção dos manipuladores das farinheiras ligadas à CAVI ocorreu pela premissa de que precisavam estar atuando em farinheiras ecológicas, que é um padrão de farinheira adotado pelo Centro de Referência em Mandiocultura do Extremo Sul da Bahia. 
Após a seleção foi feita uma visita para preenchimento e criação de um cadastro com dados das cooperativas da CAVI em relação a produção, manipuladores e cadastro de legalização da farinheira. As farinheiras ecológicas foram submetidas à Lista de verificação do Anexo I da RDC $n^{\circ}$ 275/2002 (ANVISA), para averiguação das condições higiênico-sanitárias conjuntamente com registro fotográfico.

Por meio dos resultados obtidos, foi possível instruir os manipuladores e propor alterações e adaptações às farinheiras ecológicas para adequação às normas da ANVISA, de maneira que houvesse redução de custos e menor investimento.

\section{RESULTADOS E DISCUSSÕES}

Foi produzido o material didático que gerou uma apostila e painéis orientativos para uso das BPF em farinheiras, que foram distribuídos para os estabelecimentos e para os 19 manipuladores participantes do curso. A carga horária do curso foi ministrada em 2 dias consecutivos, conforme solicitação dos manipuladores, e contou como instrutores principais a aluna bolsista e voluntários, que utilizaram de técnicas bem ilustrativas para realização do curso e garantir aprendizagem.

A aplicação da Lista de verificação das boas práticas de fabricação em estabelecimentos produtores/industrializadores de alimentos ocorreu antes do início do curso aos manipuladores para evitar interferências nos hábitos e local de manipulação. Com a lista, verificou-se que a Classificação de três estabelecimentos do tipo farinheira ecológica era Grupo 3 com média de 27,13\%, ou seja, com atendimento de 0 a $50 \%$ dos itens da lista. Esse valor encontrado é muito aquém do desejado para uma indústria de alimentos e denuncia a urgência de adequações estruturais o mais rápido possível. Nesta lista, para o item 5 MANUAL DE BOAS PRÁTICAS DE FABRICAÇÃO, por exemplo, dos 17 itens disponíveis para averiguação, nenhum deles foi atendido.

Figura 1: Registros de atividades com a turma durante a capacitação. 


\section{CONSIDERAÇÕES FINAIS}

Ao término da atividade, foram treinados 19 manipuladores que atuam nas 3 farinheiras ecológicas da CAVI que estão em processo de adequação, mudanças no processamento e na infraestrutura para a produção de derivados de mandioca, conforme estabelecem as normas do MAPA e ANVISA, além da regularização para produção de farinha pela Secretaria de Agricultura do município de Alcobaça/BA. Embora não tenha sido coletada e nem catalogada a quantidade de farinheiras que existem na região, estima-se que existam mais de 400 farinheiras somente neste município. Percebeu-se que os manipuladores de alimentos foram sensibilizados sobre a importância higiênico-sanitária para produção de alimentos, instruídos e treinados a utilizar as boas práticas de fabricação de alimentos e apresentam-se aptos como reprodutores da importância da produção de alimentos seguros para o consumidor. Como complemento a este estudo, sugere-se continuação desse processo de treinamento e capacitação de manipuladores para todas as farinheiras da Cooperativa do Vale do Itaitinga - CAVI, contribuindo para melhoria da infraestrutura das unidades, da economia e da comunidade local.

\section{PRINCIPAIS REFERÊNCIAS}

BRASIL, Resolução RDC n ${ }^{\circ}$ 216, de 15 de setembro de 2004. Dispõe sobre Regulamento Técnico de Boas Práticas para Serviços de Alimentação. Disponível em: $<$ http://portal.anvisa.gov.br/documents/> Acesso em: 20 de março de 2019.

BRASIL, Resolução de Diretoria Colegiada RDC No 275, DE 21 DE OUTUBRO DE 2002. Dispõe sobre o Regulamento Técnico de Procedimentos Operacionais Padronizados aplicados aos Estabelecimentos Produtores/Industrializadores de Alimentos e a Lista de Verificação das Boas Práticas de Fabricação em Estabelecimentos Produtores/Industrializadores de Alimentos. Disponível em: < http://portal.anvisa.gov.br/documents/> Acesso em: 20 de março de 2019.

BRASIL, Resolução do Departamento de Inspeção de Produtos de Origem Animal $n^{0} 10$, de 22 de maio de 2003. Institui o Programa Genérico de PROCEDIMENTOS - PADRÃO DE HIGIENE OPERACIONAL - PPHO, a ser utilizado nos Estabelecimentos de Leite e Derivados que funcionam sob o regime de Inspeção Federal, como etapa preliminar e essencial dos Programas de Segurança Alimentar do tipo APPCC (Análise de Perigos e Pontos Críticos de Controle). Disponível em: $<$ https:// www.defesa.agricultura.sp.gov.br>. Acessado em: 10 de abril de 2019. 